NiCE Working Paper 09-104

January 2009

\title{
Institutions and the Relation between Corruption and Economic Growth
}

Wouter Ebben

Albert de Vaal

Nijmegen Center for Economics (NiCE)

Institute for Management Research

Radboud University Nijmegen

P.O. Box 9108, 6500 HK Nijmegen, The Netherlands http://www.ru.nl/nice/workingpapers 


\title{
Institutions and the relation between corruption and economic growth
}

\author{
Wouter Ebben \& Albert de Vaal* \\ Radboud University Nijmegen
}

January 2009

\begin{abstract}
We study the effects of corruption on economic growth in a framework that includes corruption as part of the institutional setting of countries. Using a formal growth framework where corruption affects labor inputs and the provision of public goods, we find that particularly in situations where institutions are not well developed corruption may be conducive to growth. In these instances the positive effect of corruption on the working of the institutional system outweighs the negative direct effects of corruption on growth. We also find that the interaction among institutions themselves matters. This underscores the importance of taking into account the complete institutional setting when studying corruption, both in theory as well as in empirics.
\end{abstract}

\section{Introduction}

The United Nations' top anti-crime official, Antonio Costa, estimates that Zaire and Nigeria, two of Africa's hardest-hit states, have lost some $\$ 5$ billion

${ }^{*}$ We thank Robbert Maseland for his useful comments and suggestions. Please send all correspondence to A. de Vaal, Nijmegen School of Management, Department of Economics, P.O. Box 9108, 6500 HK Nijmegen, the Netherlands. Email: a.devaal@fm.ru.nl 
each in the last few years to corruption. In Pakistan, an estimated 30 percent of the price of all public works projects goes to kickbacks and bribes, while in Bangladesh corruption eats up about half of all foreign investments (Stevenson, 2003). But corruption is not only a third-world phenomenon. While it is undeniably more prevalent in authoritarian less developed countries, also democratic, western societies are not free of corruption. For example, a 2002 parliamentary enquiry in the Netherlands showed that the Dutch construction industry participated in illegal practices, ranging from fraud, unjustified subsidies and license issuance to real bribery and money or favours to individual politicians or higher-ranking public servants (van den Heuvel, 2005). Overall, a World Bank Institute study estimates the costs due to corruption in both rich and developing countries to be a $\$ 1000$ billion a year (World Bank, 2004). Other studies show that corruption is detrimental to growth as it lowers domestic investments (Mauro, 1995), the inflow of foreign direct investments (Wei, 1997), international trade (Lambsdorff, 1999) or the productivity and quality of public investment projects (Tanzi \& Davoodi, 1997). Furthermore, Mo (2001) shows that corruption creates sociopolitical instability which, by creating uncertainty, lowers productivity and economic growth.

Empirically, there is broad consensus that corruption is detrimental to the economic performance of countries on the long term. This is in sharp contrast with the theoretical literature on corruption and growth. For a long time corruption was treated as a standard distortion. With corruption, resources are spent on bribery instead of production, reducing the efficient allocation of resources and hampering economic growth. However, there are also alternative views. Leff (1964), for instance, argues that those criticizing corruption often seem to have in mind bureaucracies that are working to promote economic development. But if governments are primarily interested in reaching other goals (e.g. staying in control, self-enrichment), a re-evaluation of the effects of corruption may be warranted. Bribery then allows entrepreneurs to gain influence on the decision-making process, fostering economic performance by reducing uncertainty and supporting the innovative activities of entrepreneurs. A similar view is expressed by Huntington (1968), who stresses the 
role of corruption in greasing the wheels of bureaucracy. Bribery can be an effective way of surmounting laws or regulations that hamper economic activity. By the same token: when government procedures are dilatory, speed money might help to speed up bureaucratic decision making. Finally, it is argued that corruption enhances growth due to bribe bidding competition. As more efficient entrepreneurs can afford to offer higher bribes, corruption facilitates that projects are assigned to the most efficient firms (Beck and Maher, 1986; Lien, 1986).

These views are not uncontested. Myrdal (1968) argues that the practice of speed money gives incentives to government officials to not act efficiently and is therefore one of the reasons behind the inertia of bureaucratic systems. Regarding the alleged benefits of bribe bidding, Baumol (1990) stresses that those who can afford the highest bribe should be considered the most successful in rent-seeking. Corruption reduces growth because the most able individuals will pursue rent-seeking activities rather than socially productive activities. Murphy, Schleifer and Vishny (1991) substantiate this argument in a model of entrepreneurship and growth.

A major drawback of the theoretical literature is the fact that it disregards completely that the relationship between corruption and growth depends on its institutional environment. If at all, most authors depict the institutional framework as a black box, or study one particular institution in isolation, making it impossible to analyze corruption in interplay with other institutions. ${ }^{1}$ However, it is well-known that a close web of formal institutions, informal institutions and distortions determine the way an economy functions (e.g. North, 1990). Removing one distortion may alter this web, so that other distortions may be triggered, leaving the economy worse off. ${ }^{2}$ Consequently, the effects of corruption in a particular society cannot be studied without taking into account (the rest of) the institutional framework of that particular society. Corruption will have different effects in different institutional settings and the effects of corruption on the economy will therefore differ

\footnotetext{
${ }^{1}$ For instance, Mauro (2002), Mo (2001), Aidt, Dutta and Sena (2008), Barreto (2000) and Ehrlich and Lui (1999).

${ }^{2}$ This line of reasoning is in line with the theory of second best, see e.g. Bohm (1967).
} 
from place to place and from time to time. It implies that the outcome of a certain reasoning should become dependent on the institutional setting one has in mind. Studying corruption without taking heed of the interdependencies between corruption and other institutions, as the theoretical literature does, is therefore inappropriate and may moreover lead to wrong inferences.

With this paper, we provide a theoretical framework that gives institutions a decisive role in determining the effects of corruption on economic growth. As we will show, this provides ample reason to expect ambiguous findings from the theoretical literature (be it for different reasons). In addition, it provides a theoretical underpinning for recent findings in the empirical literature that the impact of corruption cannot be explained without taking into account the institutional setting of countries. ${ }^{3}$ Ignoring the interdependency between corruption and other institutions tends to downplay the cross-country variance in the relationship between corruption and growth.

The model we develop takes these vital interdependencies into account. In particular, we construct a two-layer model to emphasize the decisive role of the institutional environment, including corruption, on the effects of corruption on growth. ${ }^{4}$ The first layer models the way corruption affects the rate of growth in an institutional vacuum. In the second layer, institutions are incorporated and modelled to assess how corruption affects economic growth through its impact on the institutional setting. Our two-layer model thus not only captures the commonly acknowledged direct effect of corruption on growth (layer 1), but also introduces a crucial indirect institutional effect of corruption (layer 2).

\footnotetext{
${ }^{3}$ Heckelman and Powell (2008) present an overview of the various empirical studies that have examined the corruption-growth relationship. They show that these studies, which generally ignore institutional measures, provide very mixed outcomes. Recent empircal studies have begun to examine corruption's impact on economic growth including the institutional environment in the analysis. They empirically show that institutions play a significant role in explaining the non-monotonic corruption-growth relation. Interesting results are provided by Méon and Sekkat (2005), Méon and Weill (2006), Méndez and Sepúlveda (2006), and Aidt, Dutta and Sena (2008). Note that this is in contrast to the earlier empirical studies which always found a clear-cut negative relationship between corruption and growth.

${ }^{4}$ The concept of using a two-layer model is taken from Ehrlich and Lui (1999), who develop a two layer model to analyse the implications of political systems on individual labour supply decisions.
} 
For the remainder of this paper it is important to be clear about what we understand under corruption. Corruption has been defined by several authors in different ways, but we adopt the definition of Macrae (1982). He refers to corruption as 'an arrangement that involves an exchange between two parties (the demander and the supplier) which (i) has an influence on the allocation of resources either immediately or in the future; and (ii) involves the use or abuse of public or collective responsibility for private ends' (Macrae, 1982, p. 678). This definition is in line with the World Bank definition that corruption is 'the abuse of public power for private benefit', but is preferred because it highlights that there are two parties involved, a briber and a bribee. Besides this, Macrae's definition makes clear that the bribee uses his public position for the benefit of his own or his relations and that it affects the allocation of resources. ${ }^{5}$ Consequently, we focus on bureaucratic corruption, involving both a public and a private party. Furthermore, we note that in our treatment of corruption, we refrain from issues of morality and solely study the economic effects of corruption, in particular economic growth.

The structure of our paper is as follows. Section 2 establishes in more detail why corruption cannot be reliably addressed in an institutional vacuum. Section 3 introduces our modelling framework and establishes the impact of corruption on economic growth when also the indirect institutional effects of corruption are taken into account. Section 4 extends our analysis to verify how outcomes depend on the particular political system that is in place, emphasizing the interdependency of institutions. Section 5 verifies what our analysis implies for social planning in the wake of corruption. Section 6 concludes.

\footnotetext{
${ }^{5}$ Further refinements of the definition are of course possible. For instance, one can make a distinction between corruption with and without theft, where the official does or does not turn over the official price of the good to the government. One can also distinguish between centralized and decentralized corruption. Centralized corruption means that once a bribe is paid, the buyer gets full property rights over the set of government goods that it buys. In decentralized corruption one bribe may not be sufficient to render effect.
} 


\section{Corruption and the institutional setting}

In a purely neoclassical setting, transactions occur under the assumption of frictionless exchange, in which property rights are perfectly and costlessly specified and information is likewise costless to acquire. Neoclassical theory has been a major contribution to economic knowledge and seems to work well in the analysis of markets in developed countries. However, when its stringent underlying assumptions are not satisfied, neoclassical theory fails to satisfactorily explain economic performance. What has been mainly missing is an understanding of the nature of human coordination and cooperation. When information is not perfect and when property rights are far from perfectly specified, cooperation is hard to realize. This is where institutions come in. When it is costly to transact, institutions matter.

Institutions are the rules of the game in a society or, more formally, the humanly devised constraints that shape human interaction (North, 1990). The major role of institutions is to reduce uncertainty by establishing a stable structure for human interaction. ${ }^{6}$ They provide a framework in which transactions and cooperation can occur under conditions that would otherwise make it extremely difficult or even impossible. Institutions can be both formal and informal. Formal rules function to facilitate socially desired kinds of exchange and to discourage the less desirable kinds (e.g. laws, contracts). These formal rules are typically supplemented by codes of conduct, norms of behaviour and conventions. These informal institutions are endogenous, embedded in the culture of a society, and change very slowly. Because formal rules deal with specific problems only and can never be exhaustive, both formal and informal institutions are essential for the working of societies. Moreover, the institutional framework is a complex system of formal and informal constraints in which only incremental changes will alter the institutional framework over time.

\footnotetext{
${ }^{6}$ This does not mean that the institutions are necessarily efficient. Laws and social norms may be inefficient, but they still perform a role in the society by reducing uncertainty. By reducing uncertainty, individuals will engage in cooperation despite the fact that they do not possess perfect information about the other players or despite the fact that the game is not repeated.
} 
Affecting the transaction costs of economic interactions, institutions are bound to influence economic performance of countries. Economic literature shows a wide array of studies on the issue of institutions and economic growth. ${ }^{7}$ However, when studying the relationship between institutions and growth, authors generally follow the notion of North (1990) that institutions affect economic performance by their effect on the cost of exchange and production. Together with the technology employed, they determine the transaction and transformation costs that make up the total costs of production. Production becomes a combination of the normal technological transformation process and a part that defines the way transactions occur. ${ }^{8}$ This last part depends on the institutional framework of a country. Good institutional settings promote economic growth by establishing an environment in which transactions occur under trust and order. Property rights are well established and people do not need to devote a lot of resources to measurement and enforcement. In such a setting, routines will be established. By contrast, bad institutions hamper economic growth because a large share of resources has to be used for accomplishing transactions, leaving fewer resources for the actual transformation process and discouraging individuals to undertake productive activities.

The relationship between institutions and economic growth is not only subject of descriptive argumentations, it also has been formalized and empirically examined. Fedderke (2001) constructs a growth model in which property rights are the institutional feature affecting economic growth. He

\footnotetext{
${ }^{7}$ Why the interplay between institutions matters for economic growth is described by Granovetter (1985), addressing the problem of embeddedness. Which institutions matter for growth is outlined in Rodrik (1999). Eicher and Garcia Penalose (2003) argues that a certain threshold level of institutional development has to be overcome, before economic growth can take off. The importance of a specific feature of the institutional framework, namely property rights, for economic growth is stressed by Gradstein (2004) and Furubotn and Pejovich (1972).

${ }^{8}$ Nelson and Sampat (2001) follow this line of reasoning by proposing that the theory of production should involve two different aspects: a recipe that is anonymous regarding any division of labour, and a division of labour plus a mode of coordination. They propose that the former is what scholars often have in mind when they think of technology in the conventional sense. This aspect is called the 'physical' technology employed. The latter aspect, which involves the coordination of human action, is referred to as the 'social capital' involved.
} 
argues that there is a mutual interdependence between institutional development and economic development. The model follows the aforementioned notion that the level of production depends on the degree of development of production technology and on the level of property rights and it formalizes that improving institutions positively influences the rate of economic growth. Empirical testing provides plenty evidence for this conclusion. Rodrik, Subramanian and Trebbi (2002) conclude that the quality of (formal) institutions is by far the most important determinant of differences in income levels between countries. In a less recent study, Scully (1988) incorporates informal institutions into the analysis and reports that the institutional framework is not only a statistically significant explanation for intercountry variations in growth rates of real per capita gross domestic product, but also that it is a phenomenon of considerable magnitude.

While the relationship between institutions and economic growth seems clear and straightforward, one should also realise that the institutional setting of a country is a close web of formal institutions, informal institutions and distortions. The interplay between these institutional factors determines whether the institutional environment fosters or depresses growth. In contrast to a neoclassical world in which all resources are used efficiently and where distortions hamper growth by definition, a more realistic picture of distortions and economic growth is provided by the concept of second-best. ${ }^{9}$ In a second best world, removing one distortion may trigger other distortions, leaving the economy worse off. The effect of removing distortions on economic growth thus depends on the way the total institutional framework changes.

This concept also applies to corruption. In a second best setting, it is by no means certain that removing corruption promotes economic growth. The effect on growth also depends on the way the removal of corruption alters the institutional setting as a whole. Corruption may be a useful element in

\footnotetext{
${ }^{9} \mathrm{Bohm}(1967)$ argues that the problem of second best applies in the real world because "the optimal-feasible allocation of resources is subject to an abundance of 'irremovable' institutional and political constraints, which seem to require other solutions to most allocation problems than what follows from a simple Pareto optimum with no other constraints taken into account than those of technology and available resources." (p. 301)
} 
the institutional web, mending or precluding other distortions. Removing corruption may then affect the economy adversely. This notion is generally missing in economic theory concerning corruption and growth, while empirically it has recently been established as relevant (e.g. Méndez and Sepúlveda, 2006; Aidt, Dutta and Sena, 2008; Heckelman and Powell, 2008). Economic literature does consider institutions, but always as an exogenous factor. It forgets that corruption itself, being a distortion, affects the relationship between institutions and growth. The total effect of corruption on growth should therefore consist of two separate effects. Apart from the obvious direct impact of corruption on growth (e.g. due to misallocation of resources), there is also an indirect effect through its impact on the institutional framework. This combination of a direct effect and an indirect institutional effect determines whether or not corruption depresses growth. By means of the direct effect, reducing corruption will be conducive to growth, but by the indirect institutional effect reducing corruption may imply lower growth rates after all.

The difficulty with incorporating these notions in economic modelling is that the institutional web is often depicted as a black box. While it is easy to acknowledge that the interplay between institutional factors determines the way institutions affect growth, it is much harder to make that tractable in economic modelling. In order to adequately model the effects of corruption on economic growth, one would have to open the black box and specify the interdependencies. This problem is also recognized by Bohm (1967), who argues that without specifying the policy restrictions that arise with second best problems, it is impossible to argue how the allocation in a second best framework is different compared to a first best allocation. For our purposes, this implies that the aspects of the institutional setting that affect the relationship between corruption and growth should be acknowledged and specified. The model would then be able to elucidate in a meaningful manner the impact of corruption on the institutional environment, specifying the conditions under which the indirect institutional effect compensates the direct stealing effect, making it possible to indicate which effects removing corruption has on economic growth. 
Since the institutional web of a country is extremely complicated and specific, it is impossible to analyze all interdependencies that influence the relationship between corruption and growth. We therefore highlight three institutional features that we believe are crucial in studying the effects of corruption on growth, i.e. political stability, property rights and the political system. We motivate our choice by the fact that these features have been acknowledged in several papers as being important determinants for growth. ${ }^{10}$

To illustrate that the institutional effect may be more than enough to compensate the stealing effect, we imagine a situation in which society is plagued by either low political stability or the absence of a decent system of property rights. In such a setting, a corrupt system may be the least of all evils, particularly in countries where ethnic differences and violent rivalries are pervasive, so that the perceived alternative to corruption is not Western-style political confrontation, but daily physical aggression (Colombatto, 2003). Efforts to eliminate corruption will then lead to political instability since corruption serves the positive function of holding society together. Also, when a decent system of property rights is missing, corruption may become a crucial element of the economic system. In such infected environment, corruption could reduce uncertainty and facilitate investments and production, thus providing an alternative system in which the indirect institutional effect of corruption more than compensates its negative stealing effect.

For political systems, it particularly matters whether corruption exists in a democratic system or in a totalitarian system. ${ }^{11}$ The key characteristic of the neoclassical paradigm that it is socially optimal if individuals strive to maximize there own benefit applies to democratic systems. Corruption is a distortion, misusing resources and infecting economic agent's incentives.

\footnotetext{
${ }^{10}$ The importance of property rights for economic growth can be found in Gradstein (2004). Colombatto (2003) presents the political system and the degree of political stability as a crucial determinant for the relation between corruption and growth.

${ }^{11}$ The perception indices in both Tanzi (1998) and Mauro (1995) show that countries with a totalitarian system have lower scores than countries with a democratic system, indicating that corruption is more present in a totalitarian system than in a democratic one. Given our focus on the effects of the policital system on the corruption-growth relationship, this is by itself not so relevant though.
} 
Of course, also modern democratic systems are far from the neoclassical ideal and welfare states have been designed to protect vulnarable groups. This creates room for corruption, also since politicians are subject to fairly loose controls. Corruption can then be a useful monitoring device, eliciting predictable behaviour (Colombatto, 2003). This applies only in the short run, however, as in the long-run bureaucrats will change their behaviour in a way that will reduce efficiency (Myrdal, 1968). In democratically orientated systems, corruption is therefore detrimental to growth.

This is different in totalitarian systems, where economic and political freedoms are limited. In particular the distinction between centralized and decentralized corruption is important. When corruption is decentralized, economic agents cannot be certain that bribing will be effective. Bribing one government official may not prevent that also other officials have to be bribed to get something done. Uncoordinated corruption leads to high degrees of uncertainty, lowering economic growth. Centralized corruption, by contrast, takes away these uncertainties as corruption has been institutionalized to serve a clear, common goal. In a way, producers can hedge the risks of uncertainty, knowing whom to bribe to secure production. In such system, corruption could be conducive to growth, especially when other institutions cannot provide for this. The distinction between decentralized and centralized corruption is related to Mancur Olson's (1993) distinction between "roving bandits" and "stationary bandits". While roving bandits are dictators trying to extract from society as much as possible, a "stationary bandit" realizes that the high levels of uncertainty this implies affects future earnings.

\section{A basic model for corruption and growth}

In this section we construct a model that acknowledges the direct and indirect effects corruption has on growth. We develop a two-layer model where the first layer models the direct stealing effect of corruption on economic growth and the second layer corruption's indirect institutional effect through its interplay with other institutions. The first layer can be seen as the con- 
ventional treatment of corruption as a distortion, whereas the second layer acknowledges that corruption also affects economic growth through its impact on the working of the institutional system.

\subsection{The first layer - corruption and growth in an in- stitutional vacuum}

The first layer follows Mauro (2002), who models corruption as lowering production and hampering the rate of economic growth. Mauro's line of reasoning is based on the well-known Barro (1990) framework, where public goods are provided by the government and act as an input for private production. Private returns to scale may be diminishing, but the social returns can be constant or increasing. Mauro incorporates corruption in this model as rent-seeking, altering the growth rate.

The economy consists of economic agents who try to maximize overall utility, as given by:

$$
U=\int_{0}^{\infty} u(c) e^{-\rho t} d t
$$

where $c$ is per capita consumption and $\rho$ represents the constant rate of time preference. The consumption good is produced by economic agents using capital, labour and public goods $G$, specifically $Y=F(K, L, G)$. This last feature represents the productive role of government in the model. However, the incorporation of the role of the government also creates room for bureaucratic corruption. Economic agents will attempt to use some of the public goods for their own benefit, instead of using them for production. In the model, individuals allocate their time between productive work, $L$, and socially unproductive stealing, $S$. Corruption therefore has two effects on output: due to rent-seeking, less time will be devoted to productive work, while it also implies that less public goods reach the production process as a productive input. Specifically, ${ }^{12}$

\footnotetext{
${ }^{12}$ In the construction of the production function we depart from Mauro in the sense that Mauro introduces a term $\phi(S)$ representing the amount of stolen goods that the rentseekers actually keep. This is assumed to be a positive function of the total amount of
} 


$$
Y=K^{1-\alpha} L^{\alpha}[G(1-S)]^{\alpha}
$$

Individuals allocate their time between productive work and rent-seeking. In equilibrium, the net wage must equal the marginal product of rent-seeking. For an individual, the marginal product of rent-seeking is $G$. When the government produces more public goods, rent-seekers can consequently appropriate a larger amount of these public goods. The marginal product of labour is the wage net of taxes which is $(1-\tau) \partial Y / \partial L$. Using equation (2), we get

$$
\frac{\partial Y}{\partial L}=\alpha \frac{Y}{L}
$$

Since the net wage must equal the marginal product of rent-seeking, the equilibrium value of $\mathrm{L}$ becomes:

$$
L=1-S=\alpha(1-\tau) \frac{Y}{G}
$$

Substituting this value of $L$ into the production function, subsequently deriving the marginal product of capital $\partial Y / \partial K$, gives rise to the following growth path:

$$
\begin{aligned}
\gamma & =\frac{(1-\tau) \partial Y / \partial K-\rho}{\sigma} \\
& =\frac{1}{\sigma}[(1-\tau)(1-\alpha) \underbrace{\left[\alpha(1-\tau) \frac{Y}{G}\right]^{\frac{\alpha}{1-\alpha}}}_{(*)}\left(\frac{1}{Y}\right)^{\frac{\alpha}{1-\alpha}} \underbrace{[G(1-S)]^{\frac{\alpha}{1-\alpha}}}_{(* *)}-\rho](3)
\end{aligned}
$$

which is essentially a tax-ridden Euler equation with $1 / \sigma$ representing the inrent-seeking in the economy, reflecting the concept of strategic complementarities: if one agent does something, it becomes more profitable for other agents to do the same thing. Because of this, the Mauro-model results in multiple equilibria: a good equilibrium with no rent-seeking and a bad equilibrium with a considerable amount of rent-seeking. Given the focus of our analysis, we want to rule out the possibility of a good equilibrium and therefore set $\phi(S)=1$. 
tertemporal substitution elasticity in consumption. The expression is by and large similar to the one derived by Mauro (2002), ${ }^{13}$ making clear that rentseeking impedes economic growth. It lowers the amount of public goods that reaches the production process (the ${ }^{* *}$-term), while it also reduces agents' optimal labour input (the *-term, equalling $1-S$ ). By that token, the inclusion of corruption also leads to an additional effect of government expenditures on growth. In addition to the Barro (1990) effects of government expenditures on economic growth $-G$ makes capital more productive but the implied tax burden also implies lower labour input - increasing government expenditures also creates more room for corruption. This leads to an increase in rent-seeking and consequently to a decrease of productive work.

\subsection{The second layer - incorporating institutions}

To incorporate the indirect institutional effect of corruption on growth, we extend the basic set-up with a second, institutional layer. Following Klein, Welfe and Welfe (1999), we extend the production function with an extra variable, in our case the importance of the institutional framework for growth. However, we also acknowledge that corruption may either facilitate or obstruct the working of institutions. Consequently, as before we model production as a function of capital, labour and public goods, but augment it with a variable $Q_{i}(S)$ that signifies the influence of the (quality of the) institutional framework on growth, while acknowledging that corruption is part of it:

$$
Y=K^{1-\alpha} L^{\alpha}[G(1-S)]^{\alpha} \cdot Q_{i}(S)
$$

Institutions are a necessary condition to produce and production is enhanced if institutional quality increases. Corruption - or stealing as we have modelled it - influences institutional quality, be it not necessarily in an adverse way. As we have argued, in societies where institutions are hardly present or do not function properly, corruption may serve to replace the lacking institutions'

\footnotetext{
${ }^{13}$ The difference is the absence of the strategic complementarity term $\phi(S)$ as a premultiplier of the $G$ terms in (3).
} 
functionality and by that have a positive effect on production. By contrast, in societies where institutions function properly, corruption has a detrimental effect on production as it obstructs the functioning of normal institutions. Labelling the former situation as corrupt and the latter as normal, we model $Q_{i}(S)$ as

$$
Q_{i}(S)=\bar{Q}_{i}+q_{i} S
$$

with $i \in\{N$ (ormal), $C$ (orrupt) $\}$. In this formulation $\bar{Q}_{i}$ denotes society's general institutional quality level (e.g. law enforcement) and $q_{i}$ determines how this institutional quality is affected by stealing. Given our discussion in the previous section, we assume that in corrupt societies stealing has a positive impact on institutional quality, and a negative effect in normal societies: $q_{N}<0<q_{C}$. Moreover, we assume that society's general institutional quality is lower in corrupt societies than in normal societies, $\bar{Q}_{N}>\bar{Q}_{C}$.

Our set-up can be easily applied to specific institutions, for instance political stability or property rights protection. Both can be seen as necessary conditions for production and development. As argued, in a situation of political stability one has a certain amount of trust and confidence, which facilitates investment and production. Political instability is therefore bound to reduce production and may even transform into a situation of anarchy and physical aggression. Also the degree of property rights protection is a key feature of the institutional setting. Without a proper system of property rights, the economic system is plagued by severe uncertainty and a functional system of property rights is therefore regarded as vital to economic growth. However, corruption may take over the role of both institutions. In a situation of high political instability, for instance, corruption is one way to hold the economic system together, or to avoid the system to explode. By the same token, when a decent system of property rights protection is lacking, corruption may affect growth positively by taking over the role of property rights.

For the growth rate, the incorporation of an indirect institutional effect of stealing implies that now also an effect arises through its impact on insti- 
tutional quality:

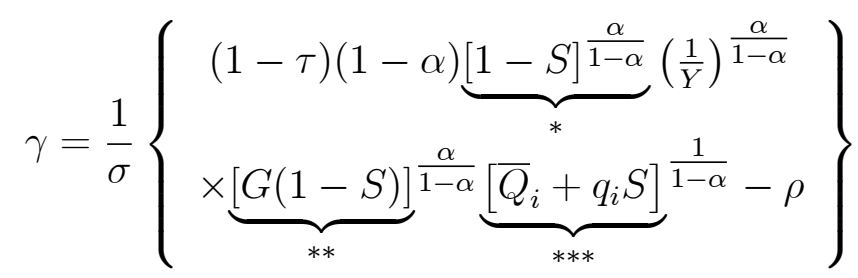

As before, stealing affects growth directly by affecting labour input choices $\left(^{*}\right)$ and by diminishing the availability of public good provision for private production $(* *)$, but now also by an indirect institutional effect (the ${ }^{* * *}$ term). This effect depends on societal circumstances: it will be negative for normal societies $\left(q_{N}<0\right)$ and positive for corrupt societies $\left(q_{C}>0\right)$. Note that there is no additional impact of stealing through its effect on optimal labour choices since labourers do not take the indirect effects of stealing into account when making their choices.

The overall effect of stealing on growth is ambiguous. Stealing reduces growth because of its negative direct effects, but due to its indirect institutional effect it may nevertheless be positive for growth after all. Formally, the effect of stealing on the growth rate is given by

$$
\frac{\partial \gamma}{\partial S} \frac{S}{\gamma}=\frac{\sigma \gamma+\rho}{(1-\alpha) \sigma \gamma} \frac{S}{1-S}\left\{\frac{q_{i}(1-S)}{\bar{Q}_{i}+q_{i} S}-2 \alpha\right\} \gtrless 0
$$

A necessary condition for the (total) effect of corruption on economic growth to be positive is $q_{i}>0$; corruption can only have a positive indirect effect in societies where normal institutions are absent or do not function properly. In such societies corruption may enhance growth provided (a) labour is not too important in production ( $\alpha$ is small), and/or (b) when stealing $S$ is not too large. ${ }^{14}$ In that case, the negative direct effects of stealing through labour choices and public good provision are small compared to the positive effect stealing has on the quality of the institutional framework. In addition, corruption is more likely to be positive for growth the lower the general quality of institutions $\bar{Q}_{i}$.

We illustrate the overall effect of stealing on growth in Figure 1, where we

\footnotetext{
${ }^{14}$ The first term in braces of (7) declines in $S$.
} 
have set $q_{N}=-1$ and $q_{C}=+1$ for convenience. The curve labeled $\gamma_{N}$ shows growth as a function of stealing for a normal society; the curves labeled $\gamma_{C}$ for a corrupt society. For normal societies, growth diminishes when stealing increases, leading to negative growth rates if stealing is too pervasive. For corrupt societies, stealing may however be conducive to growth. Given $q_{C}=$ 1 , this is the case for $S<\bar{S}_{C} \equiv\left(1-2 \alpha \bar{Q}_{i}\right) /(1+2 \alpha)$, where $\bar{S}_{C}$ is positive if and only if $2 \alpha \bar{Q}_{i}<1$. Indeed, for stealing to have a positive effect on growth labour should not be too important in production while general institutional quality should be sufficiently low. We illustrate this by displaying a curve for $\gamma_{C}$ for which institutional quality is too high for stealing to be conducive to growth $\left(\gamma_{C}^{\text {high } \bar{Q}}\right)$ and one for which it is sufficiently low $\left(\gamma_{C}^{\text {low } \bar{Q}}\right)$. Also in corrupt societies too much stealing will affect growth negatively, leading to negative growth rates if it becomes too pervasive. ${ }^{15}$

Figure 1 also illustrates that, in the presence of stealing, growth may be higher in corrupt societies than in normal societies. This is a logical consequence of the fact that in corrupt societies the indirect institutional effect of stealing is positive, where in normal societies it is negative: $\gamma_{C}>\gamma_{N}$ if $S>\tilde{S} \equiv\left(\bar{Q}_{N}-\bar{Q}_{C}\right) / 2>0$. One implication is that in societies where, for whatever reason, stealing is more pervasive, it may be advantageous to opt for a corrupt society. We will come back to this issue in the next section.

A final point is the evolution of institutional quality over time. Provided government pursues a policy of balanced budget at all times, which we assume, the growth rate of public good provision is always equal to that of aggregate output, implying that the marginal revenue of rent-seeking changes in tandem with the marginal revenue of productive work. Consequently, the levels of $L$ and $S$ that are chosen are always the same, implying an extreme form of path dependency. Whether corruption facilitates or hampers economic growth depends on society's initial situation. If that situation is such that corruption facilitates growth, it will always do so unless exogenous shocks or policy actions induce changes in the initial setting.

\footnotetext{
${ }^{15}$ The level of $S$ for which growth rates become negative is however higher for corrupt societies than for normal societies, as can be easily verified by setting the growth rate in (6) to zero, recognising that $q_{C}=-q_{N}$.
} 
(insert Figure 1 about here)

\section{The political system and corruption}

In this section we apply our two-layer framework to analyze to what extent the political system matters for the impact of corruption on economic growth. The analysis we offered so far can be seen as resembling the outcomes of corruption in a democratic system. No individual agent has power over other agents, whereas the role of government is limited to producing and distributing public goods. But also the political system, as part of the institutional setting, may have consequences for the relation between corruption and economic growth. As we discussed in Section 2, the effects of corruption in democratic systems are different from those in totalitarian systems, whereas also the particular form of the totalitarian system is relevant - Mancur Olson's (1993) distinction between "roving bandits" and "stationary bandits". Regarding government spending and taxation the distinction between "roving bandits" and "stationary bandits" is clear from the following quote from Olsen: "Their (stationary bandits) thefts were distinguished from those of roving bandits only because they took the form of continuing taxation rather than occasional plunder. [...] The rational stationary bandit will take only a part of income in taxes, because he will be able to extract a larger total amount of income from his subjects if he leaves them with an incentive to generate income that he can tax." (Olson, 1993, p. 568). "Roving bandits" are therefore characterized as dictators trying to extract from society as much as possible without taking heed of future implications; "stationary bandits" realise that future earnings are doubtful if individual agents are not left incentives to produce.

To analyze these different set-ups we retain our assumption that government collects taxes and produces public goods, facilitating private production. When there is a democratic government in place, outcomes are as in the previous section and require no further elaboration. The growth rate in the institutional vacuum is given by (3), whereas the growth rates when also 
institutional quality is taken into account is given by (6). When a totalitarian system is in place, we assume that government - the dictator - also uses tax income to serve needs that do not add to private production. When the dictator is of the roving bandit type, it will use all tax revenues for its own purposes, extracting as much from society as possible. This disables private production, obviously with disastrous effects on economic growth. For that reason, we will not further elaborate on the 'roving bandit' type of totalitarian system. When the dictator is a 'stationary bandit', things become different. Recognizing that public goods facilitate production, a stationary bandit will choose "the revenue-maximizing tax rate [...] and will spend money on public goods up to the point where his last dollar of expenditure on public goods generates a dollar's increase in his share of the national income." (Olson, 1993, p. 570).

Ignoring for now the impact of corruption on institutional quality, such optimisation stance improves economic growth when there is stealing. By rationally reducing public goods provision, the stationary bandit effectively reduces the amount of corruption in society, which is good for growth. To see this formally, we note that the marginal cost of public good provision equals one for the stationary bandit, whereas the marginal benefit is $\tau(d Y / d G)$. Of all tax revenues collected, stationary bandits will therefore spend $G=\tau \alpha Y$ on public goods, keeping the remainder selfishly for themselves. Everything else the same, public good provision is less under a stationary bandit than in a democratic society. This reduces the amount of stealing that is going on and increases the amount of labour individuals decide to supply:

$$
L_{S B}=\frac{(1-\tau)}{\tau}>\alpha \frac{(1-\tau)}{\tau}=L
$$

where $L_{S B}$ is optimal labour input under the stationary bandit regime and where the value for $L$ is taken from Section 3. Moreover, we have applied $G=\tau \alpha Y$ in case of the stationary bandit and $G=\tau Y$ in case of the democratic system. Using this in the growth function yields

$$
\gamma_{S B}=\frac{1}{\sigma}\left[(1-\tau)(1-\alpha)\left[\alpha(1-\tau) L_{S B}\right]^{\frac{\alpha}{1-\alpha}}-\rho\right]
$$


which is higher than the equivalent growth rate in a democratic system. ${ }^{16}$.

We note that this growth rate is also higher in comparison to a society where a democratic government would set public expenditures and tax rates optimal for economic growth. In such society, which is the appropriate benchmark for the 'planning' stationary bandit, government would set $G / Y=\tau$ equal to $\alpha$, which is the natural efficiency condition for government expenditures (Barro and Sala-i-Martin, 1999: 155). This implies labour input of $L=(1-\tau)<L_{S B}$. In the presence of stealing, however, the natural efficiency condition for government expenditure changes to $G / Y=\alpha \sqrt{1-\tau} \cdot{ }^{17}$ Stealing implies that it is optimal to spend a lower percentage of national income on public goods, which the stationary bandit unintentionally honours by selfishly requiring a higher marginal benefit on public goods provision.

To infer the importance of the political system in an institutional setting, we verify the implications of having a stationary bandit for the second layer of our framework. Since we know that $S_{S B}<S$, the effect of a stationary bandit on growth boils down to determining how the growth rate (6) changes when $S$ decreases. We recall from (7) that:

$$
\frac{\partial \gamma}{\partial S} \frac{S}{\gamma}=\frac{\sigma \gamma+\rho}{(1-\alpha) \sigma \gamma} \frac{S}{1-S}\left\{\frac{q_{i}(1-S)}{\bar{Q}_{i}+q_{i} S}-2 \alpha\right\} \gtrless 0
$$

Whether or not a stationary bandit enhances growth when also other institutions are taken into account thus depends on the quality of the institutional framework. From Section 3 we know that the effect of corruption on economic growth is negative in normal societies, but also in corrupt societies when institutional quality $\bar{Q}_{C}$ is sufficiently high. With $S_{S B}<S$, a stationary bandit is therefore beneficial to growth in these situations. For corrupt societies with insufficient institutional quality, however, growth may thrive upon corruption. That is, provided stealing levels are not excessively high $-S<\bar{S}_{C}$ in terms of Figure 1 - the actions of stationary bandits would be

\footnotetext{
${ }^{16}$ Eqn. (3) can be rewritten to $\gamma=\frac{1}{\sigma}\left[(1-\tau)(1-\alpha)[\alpha(1-\tau) L]^{\frac{\alpha}{1-\alpha}}-\rho\right]$.

${ }^{17}$ Recognising that part of public good production dissipates because of corruption, the government sets $(1-S) d Y / d G=1$. The expression in the text then readily follows upon substitution of $1-S=(1-\tau) \alpha Y / G$.
} 
detrimental to growth. When stealing enhances growth because of lacking institutions, a stationary bandit is uncalled for. This also underlines the mutual dependence of different institutions for generating end-outcomes (for instance property rights protection or political stability).

\section{Social planning in the wake of corruption}

Since the stationary bandit apparently has 'social planning' qualities, it is worthwhile to compare the outcomes of a stationary bandit with a democratic government that also takes on a role as social planner, a so-called rational democratic government (RDG). The distinction between RDG and stationary bandits is of course that RDG takes aggregate output as a yardstick for social planning, whereas stationary bandits would maximize their own income. In our framework, several levels of social planning are possible and we distinguish two of them. First, we see social planning as a situation in which government acknowledges that in the presence of rent-seeking individual labour input decisions are suboptimal, determining the optimal division between labour and rent-seeking itself. Second, we analyze the consequences when government recognizes that both $L$ and $S$ are functions of $G$, optimising public good provision accordingly. Apart from that we also verify what policy options social planners have to increase growth.

A social planner that optimizes labour supply choices The societal optimal value of $L$ is obtained by setting the marginal product of labour equal to that of rent-seeking. For the RDG, the former is $\alpha(Y / L)$ while the latter is: ${ }^{18}$

$$
\frac{d Y}{d S}=\left[\frac{q_{i}}{\bar{Q}_{i}+q_{i} S}-\frac{\alpha}{1-S}\right] Y
$$

This differs from the marginal product of rent-seeking for the individual, which was simply $G$. Moreover, $d Y / d S$ may only be positive in the presence

\footnotetext{
${ }^{18}$ Output also depends on stealing through the effect of stealing on $G$. This has no effect on the optimal labour input choice as we require balanced government budgets. $G$ is therefore a fixed proportion of $Y$ that is independent of $S$.
} 
of an institutional externality, particularly if $q_{i}>0$. For the stationary bandit, the relevant comparison is between the marginal effect of stealing and working on the share of tax revenues it keeps for itself, $(1-\alpha) \tau Y$. The stationary bandit thus also optimizes $L$ by setting $d Y / d L=d Y / d S$ and chooses an optimal labour input that is the same as the RDG would choose. Hence,

$$
L_{R D G}=L_{S B}=2 \alpha\left[\bar{Q}_{i}+q_{i} S\right] / q_{i}
$$

Optimal $L$ is positively correlated with the presence of stealing in society only if $q_{i}>0$, as in a corrupt society. In that case, the positive externality stealing implies for institutional quality is internalized by both RDG and the stationary bandit. If this positive externality is absent, as in normal societies, the marginal benefit of stealing is negative and would imply an optimal labour supply choice of one.

Using the optimal value of $L$ from equation (9) in the growth function yields

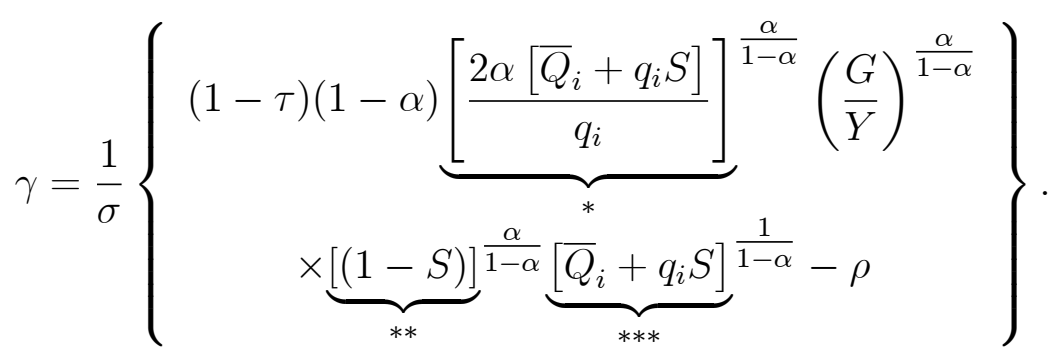

The main difference with the growth equation we had before is that the direct effect of stealing through its effect on labour input now also depends on the overall institutional quality of society, cf. the *-term in (10) with that in (6). This effect arises because the social planner acknowledges that stealing has consequences for total output. Of course, stealing only contributes positively in corrupt societies, when $q_{i}>0$. This holds for both the RDG and the stationary bandit. The growth rate will nevertheless be lower with a stationary bandit in charge, $\gamma_{S B}<\gamma_{R D G}$. The stationary bandit provides less public goods $-G / Y=\alpha \tau$ as opposed to $G / Y=\tau$ for RDG - implying that it was the planning part of the stationary bandit's behaviour that made 
the difference before, not its selfishness.

A social planner that optimizes public good provision Suppose now that social planning involves choosing the optimal level of public good provision, thereby taking into account that individual labour supply decisions depend on $G$. This boils down to assuming that government equates the marginal cost and benefits of $G$, based on an aggregate production function that incorporates the individual optimal labour supply choices we derived in Section 3. Recalling from there that $L=1-S=(1-\tau) \alpha Y / G$ and ignoring momentarily the impact of institutional quality on output, the relevant production function becomes $Y=K^{1-\alpha}[(1-\tau) \alpha]^{2 \alpha} Y^{2 \alpha} G^{-\alpha}$. Rearranging gives

$$
Y=[(1-\tau) \alpha]^{\frac{2 \alpha}{1-2 \alpha}} K^{\frac{1-\alpha}{1-2 \alpha}} G^{\frac{\alpha}{2 \alpha-1}}
$$

For the stationary bandit the marginal costs of public good provision are one and the marginal benefits amount to $\tau(d Y / d G)$. This implies

$$
G / Y=\frac{\alpha \tau}{2 \alpha-1}
$$

which is positive only if $\alpha>1 / 2$. Hence, labour must have sufficient weight in final good production to convince the stationary bandit to produce a positive amount of $G$. Provided this is the case, the stationary bandit will choose a higher level of $G / Y$ than when it did not take into account the positive impact of $G$ on stealing. To keep the stream of tax revenues in tact, the stationary bandit increases public good provision. In the absence of an institutional quality externality, this has no effect on growth rates though, as can be easily verified from $(3) .{ }^{19}$

For the RDG, the marginal costs of public good provision are one while the marginal benefits amount to $(d Y / d G)$. This yields

\footnotetext{
${ }^{19}$ The direct effect on output of higher $G / Y$ exactly cancels out against the effect of lower optimal labor input. This would of course be different had social planning involved choosing optimal $G$ from a growth perspective.
} 


$$
G / Y=\frac{\alpha}{2 \alpha-1}
$$

since balanced budget requires $G=\tau Y$ as well. Again, public good provision is positive if $\alpha>1 / 2$, in which case $G / Y$ is also higher than before. Also for a RDG it thus holds that if it acknowledges that its outlays affect stealing, it will increase public good provision.

Investigating optimal public good provision when also institutional quality matters of course alters these results. The optimal labour supply choice of individuals remains the same, so that the production function is essentially the institution quality augmented version of (11):

$$
Y=[1-\tau) \alpha]^{\frac{2 \alpha}{1-2 \alpha}} K^{\frac{1-\alpha}{1-2 \alpha}} G^{\frac{\alpha}{2 \alpha-1}} Q_{i}[S(G)]
$$

where $Q_{i}[S(G)]=\bar{Q}_{i}+q_{i} S(G)$. The implications of including $Q_{i}[S(G)]$ in the production function may be verified from $d Y / d G$ :

$$
\frac{d Y}{d G}=\frac{\alpha}{2 \alpha-1} \frac{Y}{G}+(1-\tau) \alpha\left(\frac{Y}{G}\right)^{2} \frac{q_{i}}{\bar{Q}_{i}+q_{i} S(G)}
$$

since $d S / d G=(1-\tau) \alpha Y / G^{2}$. The first term on the right-hand-side is the expression for $d Y / d G$ in institutional vacuum. Including institutional quality therefore implies that if stealing affects institutional quality positively $\left(q_{i}>0\right), d Y / d G$ goes up. In a corrupt society, it is optimal for both RDG and the stationary bandit to increase spending on public goods. Since individual labour supply decisions do not take this externality into account, the impact on growth is however still zero, see (6).

A social planner that optimizes growth Social planning may also involve thinking about which system is optimal for growth. Referring back to Figure 1, it is clear that for high levels of stealing in society, a social planner would prefer a corrupt system, while for low levels of stealing, a normal society would be preferable. This goes for both a RDG and a stationary bandit, as higher growth implies higher future tax revenues. The desirability of either system depends on the general institutional quality in both systems. 
The larger the difference, the smaller the range of $S$ values for which the corrupt system is desirable. In the figure this can be easily checked by comparing the points of intersection of both $\gamma_{C}$ curves with the $\gamma_{N}$ curve and what it implies for $\tilde{S}$, the threshold level beyond which the corrupt system features higher growth rates. ${ }^{20}$

However, the level of stealing in society may not be optimal for growth. In normal societies, it is clear that growth is highest when stealing is zero. This is also the case in corrupt societies when the institutional effect is low enough. In corrupt societies, however, stealing levels may be too low from a growth point of view $\left(S<\bar{S}_{C}\right)$ or too high $\left(S>\bar{S}_{C}\right)$. In such societies fighting corruption is therefore not always optimal for growth. Of course, to the extent that corrupt societies coincide with high levels of stealing, fighting corruption is beneficial in corrupt societies as well. Apart from fighting corruption to increase growth, a social planner could also consider changing the general quality of society's institutions $\bar{Q}_{i}$. Such endeavour would shift the growth curves in Figure 1 up, while also lowering $\bar{S}_{C}$, so that increasing general institutional quality increases growth for both types of society.

This begs the question what is more effective for boosting growth, fighting corruption or investing in better institutions? For high levels of stealing, it is clear that reducing stealing is more effective. For high $S$, the marginal impact on growth of reducing stealing is higher than the marginal impact of increasing $\bar{Q}_{i}{ }^{21}$ For lower levels of $S$ this becomes different. For example, in the vicinity of $\bar{S}_{C}$, the effect of fighting crime on growth rates in the corrupt regime goes to zero and may even become negative, so that it is better to increase $\bar{Q}_{C}$. This also implies that in corrupt societies growth rate increasing strategies may have to change over time. While fighting corruption may be most effective to increase growth initially, below $\bar{S}_{C}$ such a strategy becomes counterproductive and investing in institutional quality becomes the right strategy. To a much lesser extent this is also true in normal societies, since

\footnotetext{
${ }^{20}$ Recall that $\tilde{S} \equiv\left(\bar{Q}_{N}-\bar{Q}_{C}\right) / 2>0$.

${ }^{21}$ The elasticity of $\gamma$ with respect to $S$ is given by see (7) and goes to $-\infty$ when $S \rightarrow 1$. The elasticity of $\gamma$ with respect to $\bar{Q}_{i}$ equals $\frac{\sigma \gamma+\rho}{(1-\alpha) \sigma \gamma} \frac{\bar{Q}_{i}}{\bar{Q}_{i}+q_{i} S}$, which is finite for all $S$.
} 
also then the relative effectiveness of improving institutional quality increases when stealing is reduced.

We finally note that when a social planner could choose both the optimal stealing level as well as society's stance (normal, corrupt), Figure 1 makes clear it would choose the normal regime and $S=0$, as it can be easily proved that $\left.\gamma_{N}\right|_{S=0}>\left.\gamma_{C}\right|_{S=\bar{S}_{C}}$.

\section{Conclusion}

A major drawback of much of the empirical and theoretical literature regarding corruption and economic growth is that it disregards that the relationship between corruption and growth depends on the institutional environment. While recent empirical papers report institutions to play an important role in the corruption-growth relationship, most authors depict the institutional framework as a black box, implying an impossibility to analyze corruption in interplay with other institutions. However, it is a close web of formal institutions, informal institutions and distortions that determines the way an economy functions. Removing one distortion may alter this web, triggering other distortions and leaving the economy worse off than before. The effect of corruption on economic growth can therefore not be studied without taking into account the rest of the institutional framework.

The model we develop in this paper tries to take (some of) these vital interdependencies into account. We construct a two-layer model in which the first layer treats the relation corruption-growth in an institutional vacuum, while the second layer adds institutional quality to assess how this alters the impact of corruption on growth. Institutions we have in mind are political stability and property right protection.

The model's first layer can be seen as the conventional treatment of corruption as a distortion by showing that, in an institutional vacuum, corruption depresses growth by lowering both the input of productive public goods and labour. The relationship between corruption and growth becomes ambiguous, however, when institutions are taken into account in the second layer. Depending on societal circumstances, corruption affects the working of 
the institutional system either positively or negatively. Corruption can foster growth when its indirect effect through the working of the institutional system is positive and more than enough to compensate for the direct negative effect following from the first layer. The model shows that for corruption to have a positive effect on growth, labour should not be too important in production while general institutional quality should be sufficiently low. The initial institutional environment is important for determining the corruptiongrowth relationship. In our set-up this path dependency takes an extreme form, since in steady-state the trade-off between work and corruption is constant. If the initial situation is such that corruption facilitates or hampers growth, it will always do so unless exogenous shocks or policy actions induce changes in the initial setting.

Also the political system affects the corruption-growth relationship. Using our two-layer model to compare between corruption in a democratic society and corruption in a totalitarian system, we find that in democratic societies the amount of corruption will be higher than in autocratic systems. Whether or not this promotes economic growth again depends on the initial societal, institutional circumstances.

It appears, however, that it is the planning part of the totalitarian autocrat's behaviour that makes the difference, not its selfishness. Ceteris paribus, a rational democratic government that acts as a social planner generates a higher growth rate than the totalitarian autocrat. These findings underline the mutual dependency of different institutions for generating outcomes and proves our premise that corruption, being an institutional factor, should be studied in close interaction with other aspects of the institutional environment. The interaction between the political system and other institutions is important for the relationship between corruption and economic growth. The extension of our two-layer model with a political system can be seen as a first step in opening the institutional black box and in applying it to a formal growth framework.

This modelling framework allows us to analyse the efficacy of different corruption-fighting strategies. In societies plagued by high levels of corruption, fighting corruption may be most effective to increase growth initially. 
However, when corruption has some valuable effects on the working of institutions, maintaining corruption-fighting tends to be counterproductive in these societies. In the end, investing in institutional quality is the right path to growth.

Furthermore, our model provides an explanation for the ambiguous findings in theoretical literature, just as it provides a theoretical underpinning for recent findings in the empirical literature that institutions may be a source of the found non-linearity of the corruption-growth relation. While results show that the corruption-growth relationship depends on the institutional environment, authors generally ascribe this to Huntington's greasing-the-wheelshypothesis (e.g. Heckelman and Powell, 2008). Our modelling framework offers a deeper theoretical basis for understanding how corruption affects growth through the institutional framework, which empirical analyses could verify.

We would like to emphasize that our argumentation and modelling should be considered as a first attempt to formalize the view that institutional factors must be studied in close interaction with the entire institutional environment. Therefore, our analysis is all but complete and many challenges lie ahead. Furthermore, we have only partially succeeded in analyzing the interplay between several institutional factors. Our model also entails an extreme form of institutional path dependency, since only exogenous changes are capable of changing existing corruption-growth paths. We believe, however, that our modelling framework could serve as a useful guideline for future analyses of corruption, institutions and economic growth.

\section{References}

[1] Aidt, T., J. Dutta, and V. Sena, 2008, "Governance regimes, corruption and growth: Theory and evidence," Journal of Comparative Economics, $36,195-220$.

[2] Barreto, R., 2000, "Endogenous Corruption in a Neoclassical Growth Model", European Economic Review, 44, 35-60. 
[3] Barro, R.J., 1990, "Government Spending in a Simple Model of Endogenous Growth", The Journal of Political Economy, 98 (5), Part 2: The Problem of Development: A Conference of the Institute for the Study of Free Enterprise Systems, 103-125.

[4] Barro, R.J. and X. Sala-i-Martin, 1999, Economic Growth, The MIT Press, Cambridge.

[5] Baumol, W., 1990, "Entrepreneurship: Productive, Unproductive and Destructive", The Journal of Political Economy, 98 (5) Part 1, 893-921.

[6] Beck, P. and M.W. Maher, 1986, "A Comparison of Bribery and Bidding in Thin Markets", Economic Letters, 20(1), 1-5.

[7] Bohm, P., 1967, "On the Theory of "Second Best"", The Review of Economic Studies, 34 (3), 301-314.

[8] Boyd, R. and P. Richardson, 1985, Culture and the Evolutionary Process, University of Chicago Press, Chicago, Illinois.

[9] Colombatto, E., 2003, "Why is Corruption Tolerated?", The Review of Austrian Economics, 16 (4), 363-379.

[10] Ehrlich, I. and F. Lui, 1999, "Bureaucratic Corruption and Endogenous Economic Growth", The Journal of Political Economy, 107 (6), part 2, 270-293.

[11] Eicher, T. and C. Garcia Penalosa, 2003, Growth with Endogenous Institutions, Draft Version 2b, 1-31.

[12] Fedderke, J., 2001, "Growth and Institutions", Journal of International Development, 13, 645-670.

[13] Furubotn, E.G. and S. Pejovich, 1972, "Property Rights and Economic Theory: A Survey of Recent Literature", Journal of Economic Literature, 10 (4), 1137-1162. 
[14] Gradstein, M., 2004, "Governance and growth", Journal of Development Economics, 73, 505-518.

[15] Granovetter, M., 1985, "Economic Action and Social Structure: The Problem of Embeddedness", American Journal of Sociology, 91 (3), 481510.

[16] Heckelman, J.C. and B. Powell, 2008, "Corruption and the Institutional Environment for Growth", Research Working Paper No. 2008-6, Department of Economics, Suffolk University, Boston.

[17] Heuvel, van den G., 2005, "The Parliamentary Enquiry on Fraud in the Dutch Constuction Industry, Collusion as Concept Between Corruption and State-Corporate Crime", Crime, Law and Social Change, 44 (2), 133-151.

[18] Hofstede, G., 2001, Culture's Consequences: comparing values, behaviors, institutions and organizations across nations, Thousand Oaks, Sage.

[19] Huntington, S., 1968, Political Order in Changing Societies, Yale University Press, New Haven.

[20] Husted, B., 1999, "Wealth, Culture and Corruption", Journal of International Business Studies, 30 (2), 339-359.

[21] Klein, L.R., A. Welfe and W. Welfe, 1999, Principles of marcroeconometric modelling, Elsevier, Amsterdam.

[22] Lambsdorff, J.G., 1999, "Corruption in Empirical Research - A Review", Transparency International Working Paper, Transparency International, Berlin.

[23] Leff, N.H., 1964, "Economic Development Through Bureaucratic Corruption", American Behavioral Scientist, 8 (3), 8-14.

[24] Lien, D.H.D., 1986, "A Note on Competitive Bribery Bames," Economics Letters, 22(4), 337-341. 
[25] Macrae, J., 1982, "Underdevelopment and the Economics of Corruption: A Game Theory Approach", World Development, 10 (8), 677-687.

[26] Mauro, P., 1995, "Corruption and Growth", The Quarterly Journal of Economics, 110 (3), 681-712.

[27] Mauro, P., 2002, "The Persistence of Corruption and Slow Economic Growth", IMF Staff Papers, 51 (1), IMF, Washington. D.C.

[28] Méndez, F. and F. Sepúlveda, 2006, "Corruption, Growth and Political Regimes", European Journal of political Economy, 22, 82-98.

[29] Méon, P-G.. and Sekkat, S., 2005, "Does Corruption Grease or Sand the Wheels of Growth?", Public Choice, 122, 69-97..

[30] Méon, P-G.. and L. Weill, 2006, "Is Corruption an Efficient Grease? A Cross-Country Aggregate Analysis", Paper presented at the EPCS congress, Turku, 20-23 April 2006.

[31] Mo, P.H., 2001, "Corruption and Economic Growth", Journal of Comparative Economics, 29, 66-79.

[32] Murphy, K., A. Shleifer and R. Vishny, 1991, "The Allocation of Talent: Implications for Growth", The Quarterly Journal of Economics, 106 (2), 503-530.

[33] Myrdal, G., 1968, Asian Drama: An Inquiry into the Poverty of Nations, Pantheon, New York.

[34] Nelson, R. and B. Sampat, 2001, "Making sense of Institutions as a Factor Shaping Economic Performance", Journal of Economic Behavior E) Organization, 44, 31-54.

[35] North, D., 1990, Institutions, Institutional Change and Economic Performance, Cambridge University Press, Cambridge.

[36] Olson, M, 1993, "Dictatorship, Democracy and Development", The American Political Science Review, 87 (3), 567-576. 
[37] Rodrik, D., 1999, "Institutions for High-quality Growth: What are they and how to acquire them", Paper presented at the International Monetary Fund Conference on Second-Generation Reforms, Washington, D.C., 8-9 November 1999.

[38] Rodrik, D., A. Subramanian and F. Trebbi, 2002, "Institutions Rule: The Primacy of Institutions over Geography and Integration in Economic Development", Journal of Economic Growth, 91 (2), 131-165.

[39] Scully, G.W., 1988, "The Institutional Framework and Economic Development", The Journal of Political Economy, 96 (3), 652-662.

[40] Stevenson, M., 2003, "UN Countries Reveal Costs of Corruption", Global Policy Forum (http://www.globalpolicy.org).

[41] Tanzi, V., 1998, "Corruption Around The World; causes, consequences, scope and cures", IMF Working Paper 98/63, IMF, Washington, D.C.

[42] Tanzi, V. and H. Davoodi, 1997, "Corruption, Public Investment, and Growth", IMF Working Paper 97/139, IMF, Washington, D.C.

[43] Weber, M. 1992, The Protestant Ethic and the Spirit of Capitalism [transl. Talcott Parsons 1930], (orig. published as M. Weber (1904-5) Die Protestantische Ethik und der Geist des Kapitalismus, Archiv für Sozialwissenschaft und Sozialpolitik XX and XXI) London, New York: Routledge.

[44] Wei, S-J., 1997, "How Taxing is Corruption on International Investors?", NBER Working Paper 6030, NBER, Washington DC.

[45] Williamson, O., 2000, "The New Institutional Economics: Taking Stock, Looking Ahead" Journal of Economic Literature, XXXVIII, 595-613.

[46] World Bank, 2004, Governance and Anticorruption (GAC), ongoing research, Washington: World Bank. 
Figure 1: The impact of stealing on growth when institutions matter

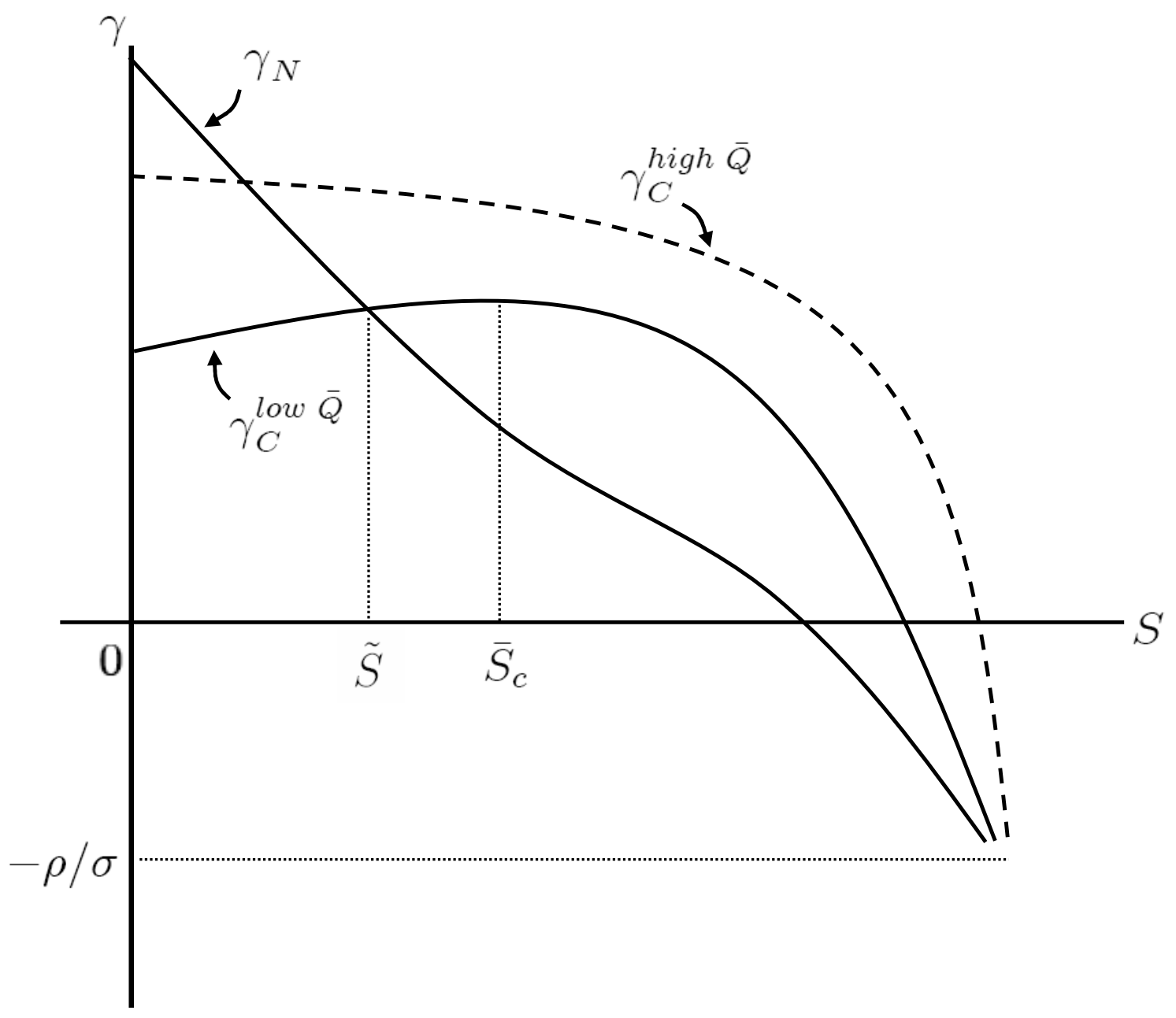

